\title{
Metodología para la construcción del Inventario de Recursos Paisajísticos en la Quebrada de Humahuaca (Argentina), Patrimonio Mundial
}

Mónica-Rossana Ferrari. Universidad Nacional de Tucumán, San Miguel de Tucumán, Argentina.

Luis-Alberto Bruna. Universidad Nacional de Tucumán, San Miguel de Tucumán, Argentina.

RESUMEN | La sostenibilidad futura del paisaje es un tema pendiente en las agendas latinoamericanas e involucra un proceso de gestión del territorio que se inicia con el conocimiento del mismo y finaliza con la propuesta de regulaciones para su protección u ordenamiento. En este contexto, el artículo muestra los avances de una investigación que propone, como herramienta clave, la elaboración de un inventario de recursos paisajísticos para la región de la Quebrada de Humahuaca, Jujuy, Argentina. Se expone como resultado una metodología -originada en la necesidad de reconocimiento, valoración y protección del paisaje- que comprende la recopilación y evaluación de la información, así como el registro de los recursos paisajísticos y su georreferenciación.

PALABRAS CLAVE | gestión territorial, patrimonio, capital cultural.

ABSTRACT | The future sustainability of the landscape is a pending issue in the Latin American agendas and involves a process of land management that begins with knowledge development and ends with the proposal of regulations for its protection. In this context, the article shows the advances of an investigation that proposes the elaboration of the inventory of landscape resources of the Quebrada de Humahuaca, Jujuy, Argentina, as a key tool. As a result, a methodology-originated in the need for recognition, valuation and protection of the landscape-is exposed, which comprises the gathering and evaluation of information, as well as the registration of landscape resources and their georeferencing.

KEYWORDs | territorial management, heritage, cultural capital. 


\section{Introducción}

Desde Carl Sauer (1925) en adelante, los estudios de paisajes culturales se han convertido en instrumentos clave para la toma de consciencia sobre las cuestiones medioambientales y culturales, sobre todo a partir del Convenio Europeo del Paisaje (CEP) celebrado el año 2000, instancia que puso en órbita la propuesta de un concepto amplio de paisaje. En Latinoamérica, la Iniciativa Latinoamericana del Paisaje (Federación Internacional de Arquitectos Paisajistas [FIAP], 2013) desarrolla un papel protagónico al "promover el reconocimiento, la valoración, la protección, la gestión y la planificación sostenible del paisaje latinoamericano” (p. 5) e impulsar el establecimiento de Cartas Nacionales del Paisaje en Argentina, Bolivia, Brasil, Chile, Colombia, Costa Rica, Ecuador, México, Paraguay, Perú, Uruguay y Venezuela (p. 8). En el orden local, la Red Argentina del Paisaje es el ámbito donde interactúan grupos heterogéneos desde diferentes enfoques disciplinares en los planos de investigación, protección, gestión y ordenamiento del paisaje.

Nuestro posicionamiento en materia de paisaje parte de considerar la contundente relación simbiótica de lo ambiental con lo cultural, presente en diversos estudios sobre esta temática que se han convertido en referente para la gestión y ordenación del territorio. En el ámbito internacional, desde 1993 -momento en que la Unesco estableció la categoría de Paisaje Cultural como parte del Patrimonio Mundial, y los concomitantes compromisos relacionados con su cuidado, gestión y preservación - se han reconocido más de treinta sitios como Patrimonio de la Humanidad. Uno de ellos, la Quebrada de Humahuaca ( $\mathrm{QdH}$ ), fue declarado como tal en 2003. La región, situada en la provincia de Jujuy, en el norte de Argentina, está conformada por un extenso y profundo valle surcado por el río Grande a lo largo de más de $140 \mathrm{~km}$, y tiene un ancho que varía entre 1 y $3 \mathrm{~km}$ (Figura 1). A partir de la declaratoria, la patrimonialización de la QdH implicó una oportunidad para el desarrollo regional, sustentada en su acervo cultural. Esta situación significó al mismo tiempo una amenaza para el sitio, debido a diversas razones; entre ellas: i) el creciente desarrollo del turismo y la construcción de equipamientos vinculados a la actividad; ii) la falta de legislación referida a la protección paisajística y a la orientación en la práctica arquitectónica en los pequeños pueblos; iii) la ausencia de estudios referidos al Paisaje Cultural que orienten el accionar en el territorio a través de directrices y de planificaciones; y iv) la falta de inventarios y catálogos accesibles a las comunidades para el conocimiento de su herencia cultural (Ferrari \& Paterlini, 2013). Dada esta realidad, consideramos que un proceso de gestión que atienda y brinde respuesta a la realidad descrita debiera iniciarse con el conocimiento de los bienes. Desde nuestra perspectiva, el inventario de recursos paisajísticos sustentado en la identificación de los recursos naturales y culturales, de forma integral y con una mirada holística, constituye una valiosa herramienta. En virtud de ello, este trabajo atiende la problemática de cómo inventariar los recursos paisajísticos, desde la mirada sistémica, en relación con la diversidad de componentes de la QdH.

En cuanto al estado del arte, se han revisado inventarios de paisaje de diversas nacionalidades, realizados mayoritariamente por consultoras con aval institucional gubernamental. Entre los menos frecuentes se encuentran los estudios desarrollados 
por instituciones académicas u organismos dedicados a la investigación. Si bien nuestro trabajo se centra con especificidad en inventarios de recursos paisajísticos, durante la recopilación de información se han hallado antecedentes con diferentes denominaciones para la identificación de paisajes; entre ellas, estudio de paisaje, inventario de paisaje e inventario de recursos paisajísticos. Sería inapropiado establecer un concepto preciso sobre lo que implica cada término, puesto que existen diferencias metodológicas para su concepción incluso en trabajos con la misma denominación. Esto es debido a que la formulación de este tipo de estudios depende de los objetivos que se persigan, las necesidades del sitio, las escalas de estudio adoptadas y el enfoque, todo lo cual permite la construcción de un método apropiado a cada caso como si se tratase de un traje a medida.

Hasta donde conocemos y hemos revisado, el aporte de nuestro trabajo radica, fundamentalmente, en la propuesta metodológica para la ejecución del inventario del paisaje cultural de un sitio declarado Patrimonio de la Humanidad. En este marco, el reconocimiento de componentes de paisaje logrado cubre un amplio espectro en una visión integral y sistémica donde se interrelacionan lo biótico, abiótico y antrópico. Al mismo tiempo, se consideran tanto los aspectos naturales y culturales como lo tangible e intangible. De ahí que el interés de este trabajo radique en que abre una instancia en el proceso de gestión de un paisaje cultural, la QdH, con vistas a su identificación, preservación, legislación, intervención y planificación, con la colaboración -en una etapa inicial- de especialistas de diferentes disciplinas. Durante la segunda parte del trabajo se desarrollará el consenso y contrastación mediante la participación comunitaria.

Por lo tanto, se plantea como objetivo mostrar el proceso metodológico de la construcción del inventario como herramienta clave para la gestión paisajística. En consecuencia, se exponen los antecedentes de inventarios de paisaje, algunos conceptos que aportaron al proceso de construcción del inventario, la recopilación y evaluación de la información, el registro de recursos paisajísticos y su georreferenciación y, finalmente, una valoración del método.

El trabajo forma parte de los avances del Proyecto de Investigación de la Universidad Nacional de Tucumán, Argentina (PIUNT), "Desarrollo de instrumentos para la gestión del paisaje cultural en la Quebrada de Humahuaca, Patrimonio Mundial”, de cuyo equipo de investigación los autores son responsables. En referencia al equipo de trabajo, la participación de investigadores de Buenos Aires, Córdoba, Jujuy y Tucumán en el desarrollo del trabajo multidisciplinario resultó clave para la determinación del tipo de información que se emplearía y el modo de incorporar las investigaciones recogidas en los trabajos de campo propios de cada disciplina.

La colaboración en la conceptualización teórica de los componentes que integran el inventario y, finalmente, la estructura y el modo de cruzar los datos en una matriz en la que se vuelca la información, fueron producto de discusiones durante un largo periodo, hasta llegar a obtener un objeto consensuado. 

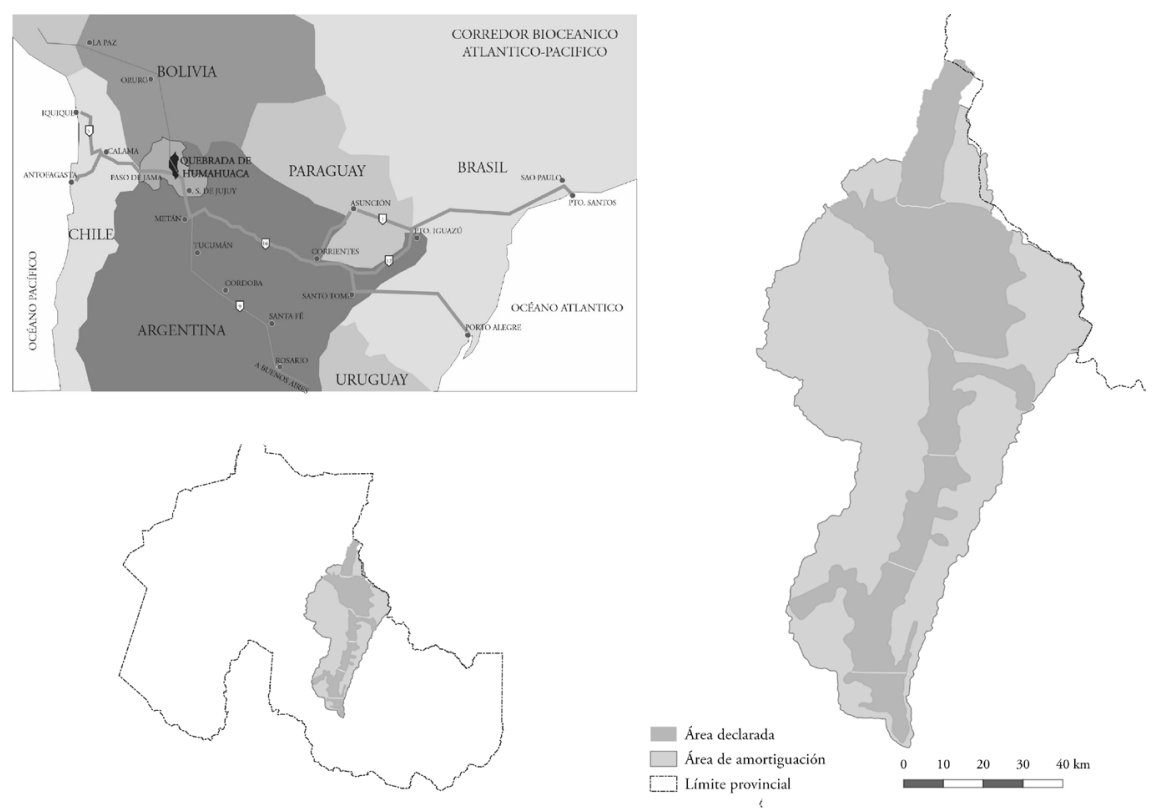

FIGURA I | Mapa de ubicación del territorio estudiado con distinción de áreas de protección y de amortiguación

FUENTE ELABORACIÓN PROPIA, CON EXCEPCIÓN DE LA UBICACIÓN CONTINENTAL Y REGIONAL (2009), ELABORADAS POR LA UNIDAD DE GESTIÓN QDH

\section{Antecedentes de inventarios de paisaje}

Existe un número creciente de iniciativas basadas en un enfoque integral para inventariar el paisaje y generar instrumentos de gestión, tales como inventarios de recursos paisajísticos, guías procedimentales o estudios para la actuación por parte de los organismos del Estado. En cada país o territorio, el documento propuesto se ajusta en función de los requerimientos, escalas y tipos de recursos paisajísticos. Del estudio derivado del análisis de inventarios hemos identificado, hasta el momento, factores que los hacen posibles y metodologías que los definen, útiles para comprender los posicionamientos teóricos, enfoques y respuestas a los requerimientos desde el propio contexto cultural. Se consultaron 17 publicaciones -la mayoría de ellas visibles en línea- que involucran a los países de Nueva Zelanda, Estados Unidos, Canadá, Ecuador, Brasil, Argentina, Francia y España.

Reconocemos cuatro factores condicionantes o posibilitantes del modo de realizar los trabajos. En primer lugar, el desarrollo del tipo de inventario de paisaje depende de la trayectoria del país en la realización de estudios -ya sea para clasificar, identificar, caracterizar y/o cualificar el paisaje-. Entre los que evidencian una gran experiencia en la producción de inventarios, algunos anteriores al CEP, puede citarse a Estados Unidos con Forest Landscape Description and Inventories, a basis for land 
planning and design (Litton, 1968), y Cultural Landscape Inventory iniciado en 1994 por National Park Service (Chalana, 2010; Brown, Hasty, Keohan \& Terzis, 2001; Page, 2009), o Reino Unido con la metodología Landscape Character Assessment (LCA) (Swanwick, 2002). En segundo lugar, el tipo de objetivo es, sin duda, una de las mayores restricciones, y su definición dependerá de si se pretende monitorear y evaluar cambios -Landscape Character Assessment (LCA) (Swanwick, 2002)-, permitir la gestión y la planificación -Junta de Andalucía (Moreira Madueño \& Naranjo, 2014)-, promover la protección y preservación -Cultural Landscape Inventory City of Mississauga en Canadá (Warrack, 2005) - o fomentar la promoción turística -Inventario de Sabinares Sierra de Cabrejas en España (Junta de Castilla y León, 2007)-. En tercer orden, la escala de estudio es un factor que va en una relación dependiente del objetivo y puede abarcar una comarca o región, como en el Inventario de Sierra Morena en Andalucía, España (Moreira Madueño \& Naranjo, 2014); un sector urbano, como el elaborado para el centro histórico de la ciudad de Washington (Page, Gilbert \& Dolan, 1998) o una reducida porción del territorio, como el caso Catálogo del Paisaje del río Suquía en la ciudad de Córdoba, Argentina (Períes, Ojeda $\&$ Kesman, 2012). Finalmente, el cuarto factor es la profundidad con que se trabaja en la obtención de datos, que depende del nivel requerido para la gestión o del alcance del objetivo principal que un inventario se proponga.

Nos centraremos a continuación en las metodologías de inventarios publicados, de las cuales resaltaremos en esta oportunidad solamente dos: la organización del trabajo y la forma de identificar el paisaje. En referencia al primer modo metodológico, es decir, a la manera de organizar el trabajo publicado, es posible reconocer tres tipos, sea en formato papel o vía electrónica. El primero corresponde a las guías metodológicas que muestran las técnicas y las pautas para desarrollar el procedimiento. En esta categoría destacan los siguientes trabajos, que se presentan cronológicamente: A Landscape Inventory Framework: Scenic Analyses of the Northern Great Plain de Estados Unidos (Litton \& Tetlow, 1978); Visual Landscape Inventory. Procedures \& Standards Manual de Canadá (British Columbia Ministry of Forests (1997) y A Guide to Cultural Landscape Reports: Contents, Process, and Techniques de Estados Unidos (Page, Gilbert \& Dolan, 1998); Cultural Heritage Landscape Inventory Background Resources (Heritage Resources Centre, 2004); Inventario. Recursos de baja intensidad. Lugar de Interés Comunitario Sabinares Sierra de Cabrejas de España (Junta de Castilla y León, 2007); Guía Metodológica para el Paisaje Cultural Ecuatoriano de Ecuador (Vázquez Estrada \& Bedoya, 2015); Inventário de paisagem cultural de Florianópolis (Bôas Camargo, Storchi \& Nór, 2015) y Guía para la elaboración de Estudios de Integración Paisajistica en la comunidad autónoma del País Vasco de España (Departamento de Medio Ambiente, Planificación Territorial y Vivienda. Gobierno Vasco, 2016).

El segundo tipo corresponde a trabajos que implican solo documentación, es decir, el desarrollo de un inventario exclusivamente, por lo general acompañado por una breve descripción de la metodología empleada. En este grupo se encuentran el Inventaire et Typologie des paysages du finistere (1995) e Inventaire des paysages de Poitou-Charentes (Aubel, Bigot, Collin \& Minier, 1999), ambos de Francia; o el 
Catálogo del Paisaje del río Suquía en la ciudad de Córdoba (Períes, Ojeda \& Kesman, 2012) en Argentina.

Por último y, en tercer lugar, podemos hacer referencia a las guías metodológicas que orientan el accionar con ejemplificaciones o estudio de casos o, en efecto, con el desarrollo del inventario completo. Integran en su primera parte un marco teórico y una explicación exhaustiva de lo que implica este tipo de documentación y cómo llevarla a cabo, hecho que resulta de alto valor por la posibilidad de comprender los alcances, objetivos y modo de proceder. En esta categoría destacan, cronológicamente, Forest Landscape Description and Inventories: A Basis for Land Planning and Design de Estados Unidos (Litton, 1968), Cultural Landscape Inventory City of Mississauga de Estados Unidos (Warrack, 2005), City of Vaughan Official Plan Cultural Heritage Landscape Inventory and Policy Study de Canadá (Williamson, 2010), Palmerston North Landscape Inventory de Nueva Zelanda (Palmerston North City Council, 2011), Bases para la realización del Sistema Compartido de Información sobre el Paisaje de Andalucía (Moreira Madueño \& Naranjo, 2014).

En cuanto al segundo modo metodológico, es decir, la forma de identificar el paisaje que se va a inventariar, algunos trabajos plantean tres posibilidades: la detección de tipos de paisaje, la identificación de componentes de paisaje, o la combinación de ambos métodos. En referencia al primero, Litton y Tetlow (1978) realizan una identificación según distintos tipos por escalas de estudio, analizando en cada una de ellas elementos tales como bordes y aristas, patrones de vegetación y de agua, formas terrestres y características locales destacadas. Por su parte, Williamson (2010) establece una clasificación tipológica funcional, según la cual se identifican complejos agrícolas, paisajes industriales, paisajes comerciales, paisajes acuáticos, paisajes ferroviarios, paisajes viales, paisajes recreativos, complejos religiosos, cementerios, sitios sagrados, paisajes artísticos, subdivisiones residenciales de posguerra y corredores de transporte del siglo xx. En otro orden, Moreira Madueño y Naranjo (2014) desarrollan un inventario a escala regional y comarcal. Para esta última establecen tipos geográficos tales como altitud, pendiente, litología, fisiografía, tamaño de parcela, asentamientos humanos, unidades fisionómicas, rangos de altura complementaria de visibilidad media y de proyección visual.

En segundo orden, entre los inventarios que trabajan exclusivamente con componentes de paisaje, Litton (1968), Litton y Tetlow (1978) y British Columbia Ministry of Forests (1997) han sido los que han tomado la delantera en tiempos anteriores al CEP con el desarrollo de componentes visuales paisajísticos. Con posterioridad al año 2000, Warrack (2005) desarrolla igualmente aspectos visuales derivados del entorno paisajístico y entorno construido, con inclusión de asociaciones históricas en sintonía con las premisas del CEP relativas a considerar los aspectos culturales. Por otro lado, la presencia de componentes naturales y culturales se encuentra en casi el $50 \%$ de los inventarios analizados, y se despliega en un espectro que abarca desde cuatro hasta una veintena de ellos en diferentes categorías y escalas. Puede verificarse en los trabajos desarrollados por Page, Gilbert y Dolan (1998), Heritage Resources Centre (2004), Warrack (2005), Chalana (2010), Períes, Ojeda y Kesman (2012), Bôas Camargo, Storchi y Nór, (2015) y Vázquez Estrada y Bedoya (2015). Otros, como el propuesto por la Junta de Castilla y León (2007), estudian componentes 
según la representatividad georreferenciada, clasificándolos primeramente en recursos puntuales, lineales y poligonales. Se llega así, y por último, al trabajo desarrollado por el Departamento de Medio Ambiente, Planificación Territorial y Vivienda, Gobierno Vasco (2016), que atiende una variedad de componentes. Estos son agrupados en tres jerarquías: i) descriptores estructurales, relacionados con el relieve, litología, agua, elementos antrópicos; ii) descriptores texturales, vinculados a usos del suelo de la cubierta vegetal, a patrones productivos y ecológicos y, iii) recursos culturales e históricos.

En lo concerniente a los inventarios que trabajan con la combinación de componentes asociados a tipos de paisajes, puede detectarse la obra de Litton (1968), destacada por estudiar paisajes según el tipo de composición visual. Por su parte, Inventaire et Typologie des paysages du finistere (Ministère de l'Equipement, 1995) y Palmerston North Landscape Inventory (Palmerston North City Council, 2011) enfatizan el trabajo con unidades de paisaje. El primero realiza una caracterización de 32 áreas según componentes inmateriales relacionados con el arte, y el segundo los desagrega en componentes. En otro orden, Cultural Landscape Inventory City of Mississauga (Warrack, 2005) es un inventario que propone pocos componentes -paisaje medioambiental, entorno construido, interés histórico o arqueológico y valor trascendental, entre otros-, donde especifica atributos de valor y realiza, al mismo tiempo, una clasificación por tipos. Dentro de este grupo, la metodología empleada por Landscape Character Assessment (Swanwick, 2002) desarrolla una identificación por componentes, para luego concentrarlos en un mapa según tipos de paisaje.

En definitiva, la utilización de una u otra metodología resulta válida, e interesan, en todos los casos, los resultados a los que se arriba. Sin embargo, en el proceso de la construcción del inventario de recursos paisajísticos para la QdH, el empleo de un inventario por componentes ha sido necesario debido a que el reconocimiento de los recursos está, en algunos casos, escasamente identificado. En ocasiones, el desconocimiento produce intervenciones que atentan contra la futura sostenibilidad del paisaje.

\section{Algunos conceptos que aportaron al proceso de construcción del inventario}

La misión del trabajo desarrollado para la QdH fue documentar lo existente con el fin de proceder a su preservación, protección y gestión. Dicha acción se complementó con lo que estableció el Consejo de Europa cuando determinó que un inventario es requerido con el objetivo de proteger, restaurar, conservar, planificar y/o educar (Bold, 2009). Una documentación de este tipo resulta compleja cuando se trata de bienes que integran varias disciplinas que operan a diferentes escalas, a tal punto que el reconocimiento del detalle, técnicamente en una escala de mayor tamaño, permite el estudio pormenorizado de los elementos que configuran cada paisaje, mientras la escala menor supone verlo desde lejos (Pérez Alberti, Borobio Sanchiz, Castillo Rodríguez \& Payán Pérez, 2014). Ese modo de identificar se realizó tomando como base el concepto de recurso paisajístico, entendido como "los elementos lineales o puntuales singulares de un paisaje o grupo de éstos que definen 
su individualidad y que tienen un valor visual, ecológico, cultural y/o histórico" (Conselleria de Territorio y Vivienda, 2006, art. 32). Las propiedades de individualidad y valor son intrínsecas de todo recurso, lo que nos permite tomar una posición global e integradora al momento de la selección y posicionarnos desde una óptica que evita tanto el reduccionismo como la consideración exclusiva de lo monumental. Entendemos, al mismo tiempo, que dichos bienes están fuertemente ligados a la definición de 'sistema', concepto que ha sido largamente usado en general en todas las ciencias, y en particular en la comprensión del hábitat, y que en ese proceso ha ido adquiriendo diferentes grados de complejidad. Adherimos al concepto de Montaner (2008), quien lo define como un conjunto de elementos heterogéneos -materiales o inmateriales- de distintas escalas, los cuales están relacionados entre sí con una organización interna que intenta estratégicamente adaptarse a la complejidad del contexto y que constituye un todo que no es explicable por la suma de sus partes. Cada parte del sistema está en función de otra y no existen elementos aislados. De este modo, entendemos que el paisaje cultural está fuertemente ligado a este concepto, por cuando su característica de inseparabilidad es justamente lo que nos permite entenderlo en su integralidad.

Desde este punto de vista, significa, en nuestro caso, superar el pensamiento simple, analítico y reduccionista para ofrecer una comprensión integrada de la realidad mediante el pensamiento complejo, como alternativa al paradigma de la simplificación. Este tipo de pensamiento se basa en la visión sistémica e integrada de la realidad -posicionamiento que hemos adoptado para la construcción del inventario-, en tanto entiende los objetos y los procesos como partes de un todo mayor. Pensada como sistema, "toda realidad puede ser concebida como una 'asociación combinatoria de partes'. La complejidad supone pensar al mismo tiempo en lo grande (en todo) y lo pequeño (las partes), en lo holístico y en lo reduccionistaanalítico" (Romero \& Mesías, 2004, p. 16). De esto deriva la adopción de diferentes escalas de aproximación al paisaje en una perspectiva totalizadora.

El concepto de holismo ha llegado a ser un principio filosófico básico de la teoría general de los sistemas. De acuerdo con esta última, el universo es considerado como "una organización, un total ordenado de una jerarquía de sistemas estratificados en varios niveles, estando cada nivel más alto, compuesto de sistemas de niveles inferiores y cualidades emergentes adicionales" (Naveh, Lieberman, Sarmiento, Ghersa \& León, 2001, p. 62). Los autores del texto citado afirman que esta teoría influyó en la visión del paisaje como un todo desarrollada a fines de la década de 1960 por el geógrafo soviético Víktor Sochava (1978), posición a la que igualmente adherimos.

Estos conceptos fueron las bases que sustentaron en forma simultánea, por un lado, el trabajo en la relación del todo y las partes; y por el otro, la comprensión de la complejidad sin perder de vista la singularidad. La extensión territorial y la vasta cantidad de recursos paisajísticos constituyeron desafíos que requirieron una estrategia basada en la flexibilidad. 


\section{La recopilación y evaluación de la información}

El aporte de la metodología que proponemos fue realizar un inventario consistente en una primera identificación de datos reunidos en forma integral. El proceso involucró siete etapas, donde las tres primeras corresponden a la instancia de recopilación y evaluación de la información, para luego continuar con el registro de la información en las fases siguientes (Figura 2).

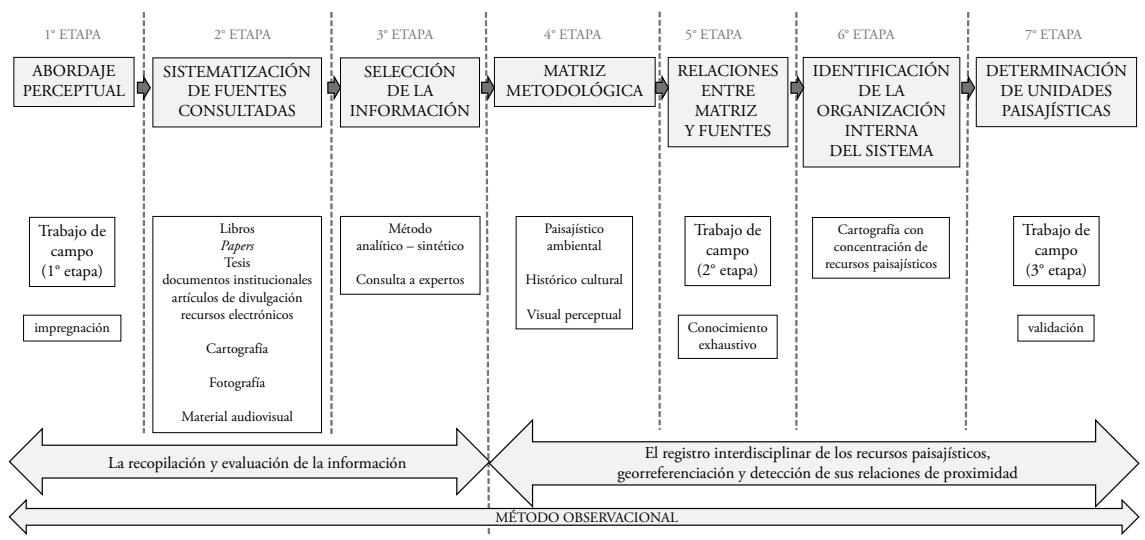

FIGURA 2 | Mapa conceptual del proceso metodológico para la construcción del inventario de recursos paisajísticos

FUENTE ELABORACIÓN PROPIA

La primera etapa se inició con el abordaje perceptual como aproximación al estudio del paisaje, entendiéndolo como un recorrido desde una mirada dispuesta a percibir y reaccionar de acuerdo con un conocimiento que está "a nivel de certeza sensorial" (Ballén Ariza, 2007, p. 10). Por lo tanto, se pudo conocer la existencia de ciertos sucesos de modo apriorístico. En esta observación no sistematizada, realizada en un primer trabajo de campo, se conoció el sitio a través de una impregnación para detectar el espíritu del lugar mediante el contacto con la gente y el reconocimiento de los aspectos naturales y culturales sobresalientes.

El punto de partida para la segunda etapa consistió en la búsqueda de información en fuentes documentales -textos, planimetrías, cartografías, informes técnicos, fotografías, audios de entrevistas, videos, material informático, etcétera-. La propuesta para la Inscripción en la Lista de Patrimonio Mundial de la Unesco (José et al., 2002) resultó clave, puesto que constituye un documento de validez por el consenso de expertos, la mirada holística y la legitimación internacional. Su importancia lo convirtió en el punto de partida esencial para el registro. Luego, la sistematización del material recopilado resultó imprescindible como parte del proceso de construcción del inventario por la magnitud de fuentes encontradas, las cuales se ordenaron según la estructura organizativa de las normas editoriales de la American Psychological Association (APA) - desde libros hasta recursos electrónicos-. De este modo, fue posible establecer un orden jerárquico de la documentación que a su vez 
permitió visualizar un universo de antecedentes de distintos enfoques disciplinares. El final del proceso arrojó como resultado un desbalance de la información según campos del conocimiento, a partir del cual se reorientó la búsqueda para obtener un soporte homogéneo.

La tercera etapa comprendió la fase de selección de la información, habiéndose considerado los siguientes criterios: clasificación temática, autoridad académica o institucional, actualización y accesibilidad. Para la clasificación temática se consideró la matriz metodológica y su organización en componentes naturales y culturales al momento de seleccionar la información. La autoridad académica o institucional se constató a través de la elección de trabajos alojados en repositorios institucionales o revistas indexadas. La actualización es relevante en el registro de algunos componentes, pues la dinámica territorial lleva a la aparición y desaparición de recursos, razón por la cual es preciso tener un estado de la cuestión. La accesibilidad se refiere a medios, mecanismos y técnicas para conseguir la información.

Al tratarse de información de gran complejidad temática, por la variedad de componentes, fue preciso adoptar un criterio de selección. Para ello, se empleó la técnica del método analítico-sintético, que permitió comprender la realidad compleja a partir del estudio por partes, para luego recomponer la totalidad. Asimismo, y como modo de superar las visiones fragmentadas y las fronteras entre disciplinas en el debate multidisciplinar, se tomó la experiencia del Instituto Andaluz de Patrimonio Histórico, que en sus prácticas laborales evidenció una comprensión compleja. Desde esta óptica, se realizó la consulta a expertos a través de talleres, lo que permitió obtener resultados relacionados con el desarrollo de la mirada holística. El encuentro fue propicio para debatir conceptos y enfoques metodológicos, construir espacios de colaboración y obtener aportes a lecturas territoriales integrales de orden complejo.

\section{El registro de recursos paisajísticos y su georreferenciación}

La cantidad extraordinaria de recursos detectados requirió el uso de un instrumento que permitiera el manejo ordenado y sistemático de los componentes. Recurrimos al empleo de una matriz, entendida como un conjunto ordenado de elementos en una estructura bidimensional. Para nuestros propósitos de investigación, en su disposición debía reflejar también los conceptos clave de nuestra propuesta metodológica: el holismo, el enfoque sistémico y el work in progress.

En esta línea, la construcción de la matriz metodológica se desarrolló, en la cuarta etapa, incorporando la diversidad de campos de conocimiento como un listado de elementos. Para ello se conformó, paralelamente, un gradiente de escalas en el eje horizontal y una clasificación tipológica para cada parte del sistema en vertical. En la estructura general, que presenta una diferenciación por áreas de interés paisajístico ambiental, histórico cultural y visual perceptual, se pudo comprender el estudio de los componentes naturales y culturales, identificando dentro de ellos los abióticos, bióticos y antrópicos. Los recursos se agruparon en disciplinas ordenadas desde la escala territorial hasta lo intangible, a saber: Geología, Paleontología, Geomorfología y Topografía, Hidrología, Flora, Fauna, Uso del Suelo, Vías de Comunicación, Servicios, Urbanismo, Arquitectura, Arqueología, Historia y Arte, y el Patrimonio 
Intangible con sus múltiples manifestaciones, a lo que se agregan las vistas y perspectivas degradadas y por preservar (Figura 3).

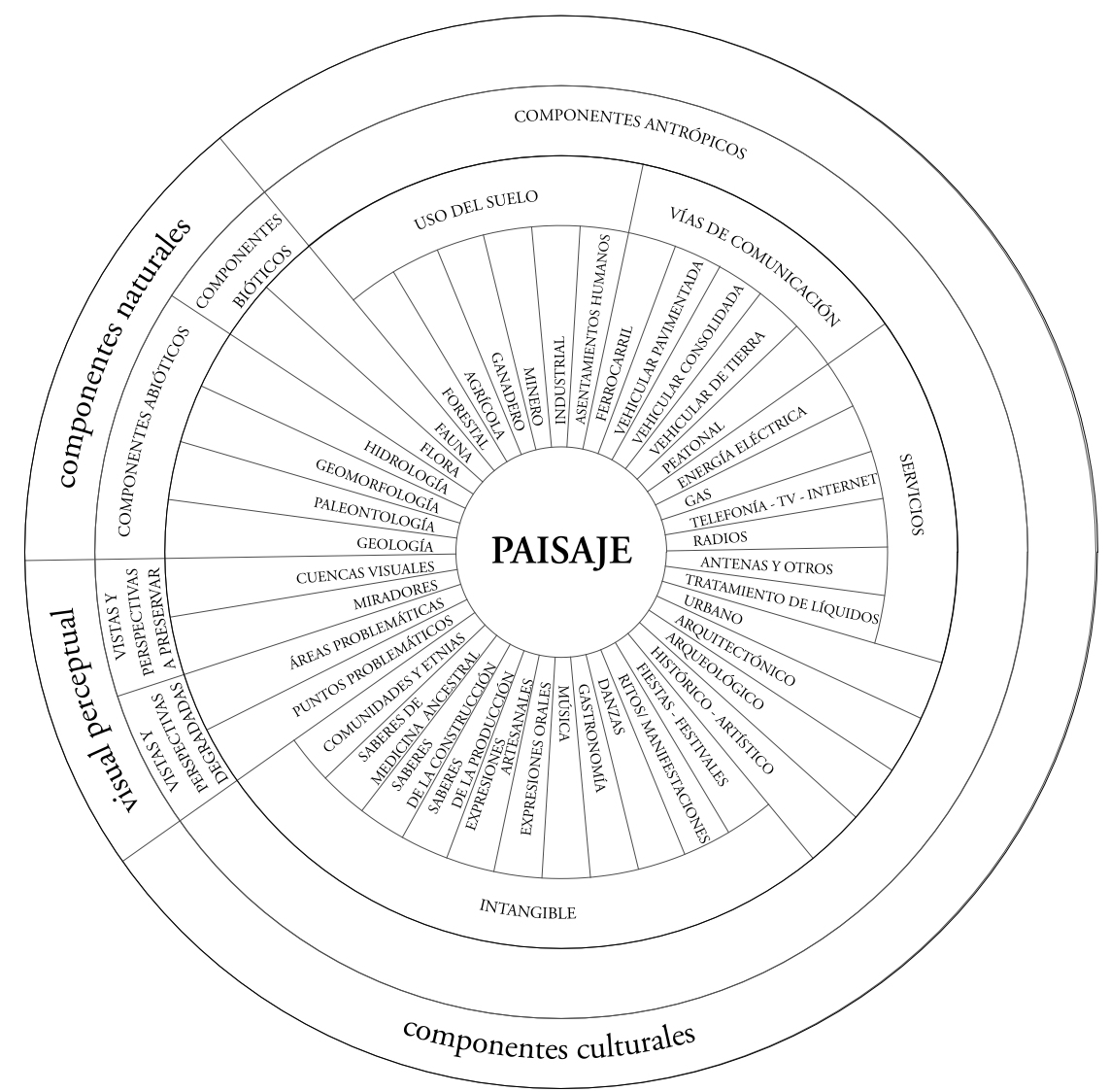

FIgURA 3 | Representación de la matriz de datos, con su clasificación en áreas de estudio, naturaleza de los componentes y definición de los campos de conocimiento

FUENTE ELABORACIÓN PROPIA

Un desafío fue la definición y los alcances de cada área del conocimiento, necesarios para evitar la superposición y considerar en algunos casos la posibilidad de repetición, al ser cada una susceptible de análisis a partir de distintas escalas. La incorporación de los recursos en la matriz se realizó considerando la posibilidad de representación como puntos, líneas o áreas en Sistemas de Información Geográfica, y requirió de tres tipos de datos para su identificación. En primer lugar, se determinó un código alfanumérico conformado por tres partes, donde la primera indica en que área de interés se incluye; la segunda establece el campo disciplinar y la tercera corresponde a la numeración de orden en la columna. En segundo lugar, se ingresó el nombre del bien según aparecía en las fuentes; en los casos de discrepancia, se 
consideró para la sistematización el correspondiente al documento de mayor jerarquía en cuanto al rigor científico de la información. En tercer lugar, se incorporaron las coordenadas de georreferenciación; para componentes lineales se tomaron como referencia los puntos extremos; y para áreas, las marcas de un polígono regular (Figura 4, Figura 5 y Figura 6). El formato digital facilitó la modificación de la edición y dejó abierta la tabla para la incorporación a futuro de bienes o componentes que necesitaran registrarse como parte de la expresión dinámica del paisaje, lo que brindó al trabajo la perspectiva de un work in progress, habiéndose registrado hasta la fecha 1300 recursos paisajísticos.

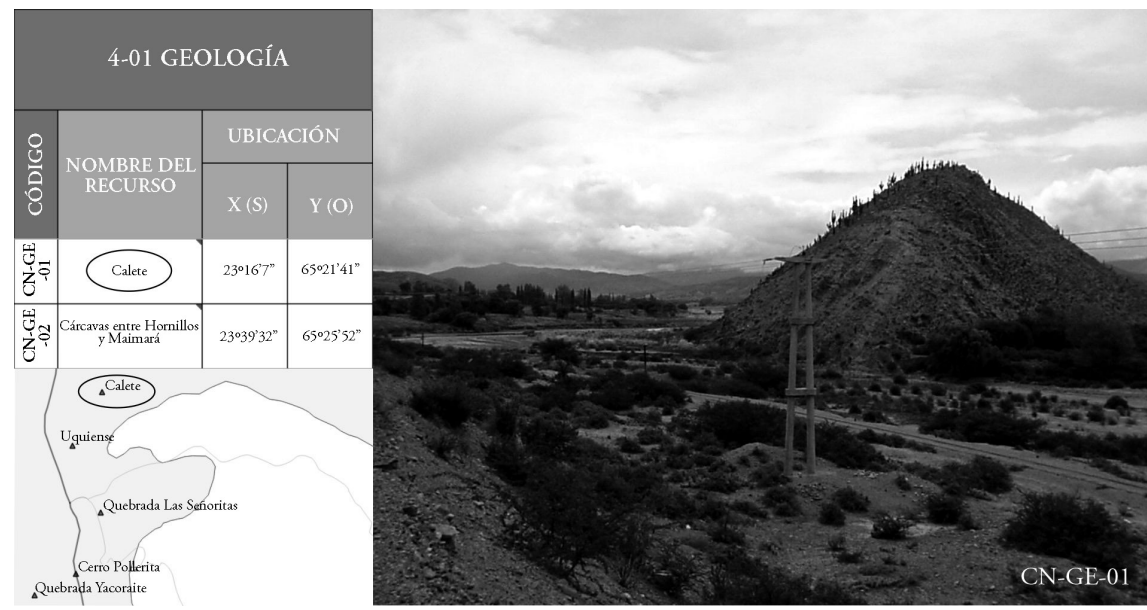

FIGURA 4 | Relación entre un sector de la matriz de datos, la cartografía y la fotografía, con codificación alfanumérica del componente geología FUENTE ELABORACIÓN PROPIA. FOTOGRAFÍA: MÓNICA FERRARI

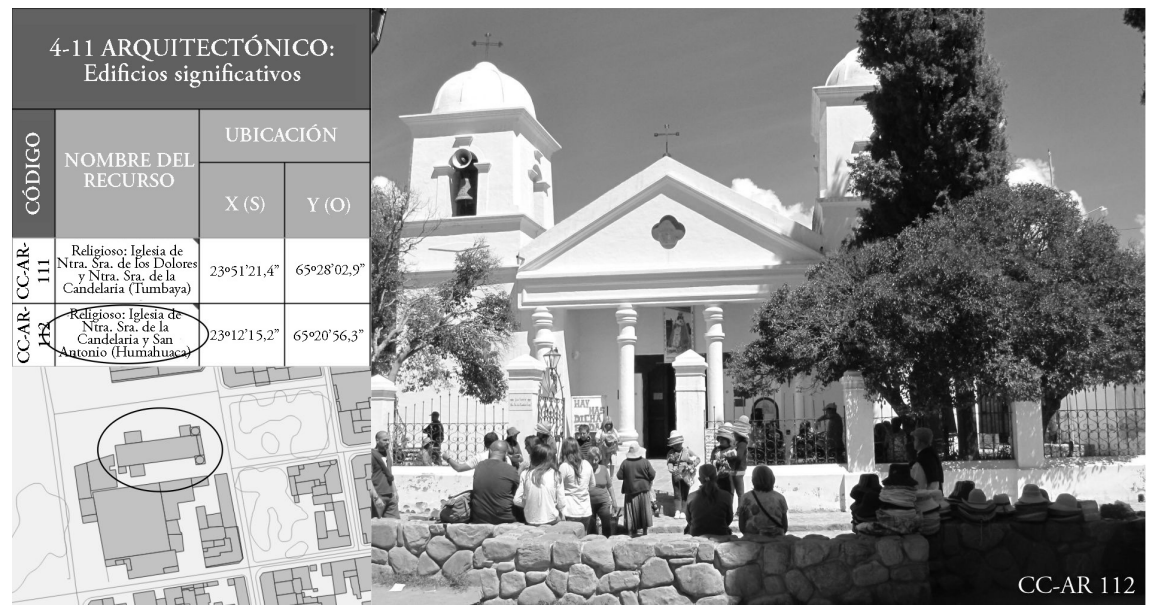

FIGURA 5 | Relación entre un sector de la matriz de datos, la cartografía y la fotografía, con codificación alfanumérica de un componente arquitectónico

FUENTE ELABORACIÓN PROPIA. FOTOGRAFÍA: MÓNICA FERRARI 


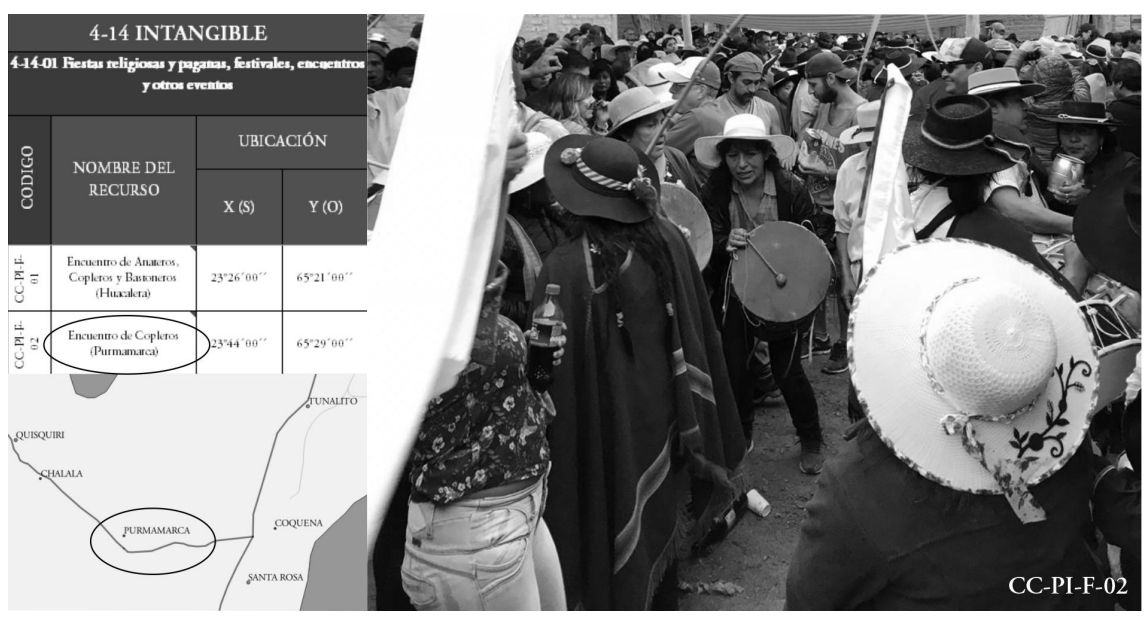

FIGURA 6 | Relación entre un sector de la matriz de datos, la cartografía y la fotografía, con codificación alfanumérica de un componente intangible

FUENTE ELABORACIÓN PROPIA. FOTOGRAFÍA: MARIANA VILLAVICENCIO

La quinta etapa estuvo determinada por trabajos de campo desarrollados en una segunda instancia, los cuales se realizaron bajo el método observacional, sistematizado con el fin de obtener información exploratoria a través de un procedimiento de tipo fotográfico-odométrico. Esta técnica permitió identificar características de algunos recursos, completándose así un conocimiento exhaustivo de los componentes. Además, se hizo una primera localización de puntos de observación, cuencas visuales y estimación de paisajes degradados y de valor, que permitió validar las relaciones entre la matriz de datos y las fuentes por la constatación in situ de trabajos previos procesados en laboratorio, tales como el establecimiento de hipótesis y la interpretación de modelos a través de la cartografía.

La validez de la matriz se puso a prueba en esta etapa cuando se debió georreferenciar los recursos paisajísticos inventariados. Para ello se trabajó en la introducción en una tabla Excel de datos que procedían de la cartografía, la fotografía, planimetrías diversas en formatos vectoriales, y aquellos provenientes de sitios como bibliotecas $\mathrm{y}$ archivos de reparticiones públicas, fondos fotográficos públicos y privados, blogs, periódicos en línea, páginas institucionales y sitios de redes sociales.

Se conformó un sistema que permitió producir material cartográfico propio y fichas para cada recurso, que serán parte del catálogo del paisaje. La relación con la cartografía se evidenció en el empleo del software de Sistemas de Información Geográfica (sIG), de libre distribución. Ello facilitó un procedimiento metódico para integrar materiales de diversas fuentes y soportes informáticos en un solo entorno gráfico, lo cual fue posible gracias a la versatilidad de los programas empleados y a la formación adquirida por miembros del equipo en el manejo de técnicas digitales. La vinculación con la fotografía se hizo presente según las imágenes obtenidas, lo que 
posibilitó ratificar las valoraciones de los recursos detectadas en los textos, además de precisar los límites visuales de los componentes -abióticos- de gran escala; y, en ocasiones, confirmar la validez de la inclusión de algunos elementos que solo se habían identificado en trabajos de campo. La diversidad y complejidad de datos procedente de fuentes, entrevistas y consultas a expertos se llevó a un plano de abstracción reducido a puntos, líneas y polígonos, y permitió ratificar el principio enunciado por Larive López y Segura Raya (2013) respecto a que "todo dato es posible y necesario de ser espacializado".

Si se tiene en cuenta que el Paisaje Cultural es un activo de gran importancia para el desarrollo económico y social, sobre todo en lugares cuya disponibilidad de recursos amerita un estudio interdisciplinar para poner en valor todo su potencial, se requiere identificar las relaciones entre la sociedad, su espacio vital y las interacciones que se generan de acuerdo con los procesos sociales y económicos. Para ello, en la sexta etapa se procedió a identificar la organización interna del sistema y se procedió a ubicar los elementos en un único instrumento cartográfico que permita, además de identificarlos en su contexto, detectar sus conflictos y anomalías. A pesar de los avances que representa la utilización de los SIG, en ocasiones la información no se encuentra disponible, con frecuencia la planimetría carece de datos como la proyección geográfica o, en algunos casos, falta información en la georreferenciación de recursos paisajísticos. Por lo tanto, fue necesario proceder en forma ordenada, siguiendo los principios tradicionales del dibujo, incorporando la diversa información cartográfica y dando coherencia a las variaciones producto de los distintos sistemas de coordenadas geográficas; luego se procedió a rectificar los shapes producidos por instituciones mediante el uso del Google Earth, y a codificarlos en shapes propios, para poder superponer y leer en forma simultánea la ubicación y las relaciones de proximidad de los recursos.

Para el abordaje del estudio de un territorio con una extensión de $5381 \mathrm{~km}^{2}$ fue necesario aproximarse al conocimiento en forma gradual a través de diferentes escalas, desde una menor a una mayor. En la primera fase, en consonancia con la escala de percepción humana, se realizó el registro de componentes según las posibilidades dadas por la accesibilidad vehicular y peatonal a los diferentes sitios que se conectan a lo largo de la quebrada. A partir de ahí, el paso siguiente fue la incorporación del dato en la matriz, con sus correspondientes coordenadas geográficas. Una segunda escala empleada ha sido la correspondiente al nivel urbano, necesaria para la lectura de relaciones entre componentes culturales, particularmente los intangibles. Finalmente se abordó la escala territorial, que permitió identificar caminos, asentamientos rurales poco accesibles, uso del suelo, etcétera. Luego del registro, una segunda fase implicó la estimación del alcance de las cuencas visuales, para lo cual se realizaron estudios de perfiles mediante el uso combinado de mapas cartográficos, Google Earth y Street View. Finalmente, y como resultado, se pudo determinar en un único sIG las áreas a escala territorial que concentraron las mayores relaciones de recursos paisajísticos a partir de la accesibilidad -transporte automotor y recorrido a pie cuando la circulación en vehículo resultaba compleja-. Se identificó de este 
modo una primera aproximación a los distintos sistemas en función de las diferentes escalas (Figura 7).

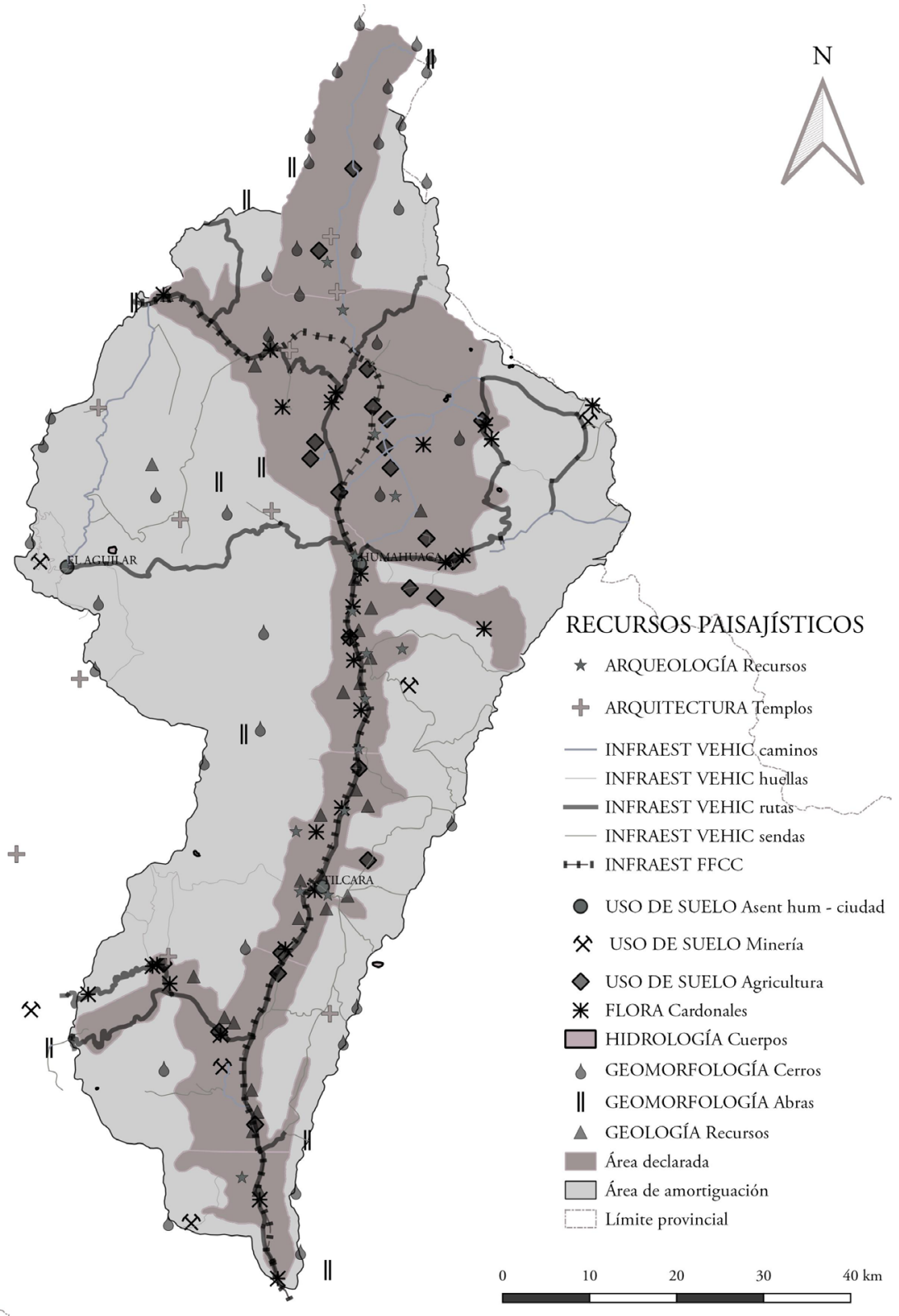

\section{FIGURA 7 | Mapa de ubicación de algunos recursos paisajísticos}

NOTA POR CUESTIONES DE VISIBILIDAD SE MUESTRAN SOLO UNOS POCOS DE LOS I 200 INVENTARIADOS HASTA EL MOMENTO

FUENTE ELABORACIÓN PROPIA 
Todo este proceso llevó al paso siguiente, la delimitación de las unidades de paisajes, en una séptima y última etapa, a partir de la concentración de recursos paisajísticos. Dicha delimitación significó una importante herramienta para la clasificación y la evaluación de las unidades de paisajes, las cuales -según Dalbem, de Moura, Jorge, Morokawa y Valaski (2005) - no pueden ser consideradas como el resultado de la simple suma de las partes. Por el contrario, constituyen una categoría superior que resulta de la interacción dinámica de sus componentes, vistos desde un enfoque integral y no de sus elementos constitutivos en forma fragmentada De este modo, según afirman los mencionados autores, el método de identificación de las unidades de paisaje lleva consigo un enfoque global de los estudios ambientales y facilita los procedimientos de evaluación del paisaje en su conjunto. En definitiva, lo que propone el trabajo brasileño es una visión desde la óptica sistémica, planteo que coincide con nuestra posición. Ahora bien, nuestro siguiente paso implicó identificar unidades de paisaje, las cuales involucraron aspectos tanto naturales como culturales. De ahí que convino precisar los criterios para definir dichas unidades desde una visión holística. El CEP (2000) ha considerado la homogeneidad como variable determinante para su estudio. En nuestro caso, la definición de unidades de paisaje dio lugar a la combinación de los aspectos naturales con los culturales.

Considerando lo anterior, las unidades de paisaje se definieron, para la Quebrada de Humahuaca, según los siguientes criterios: i) ambientales, que integran a la geología, geomorfología e hidrografía; ii) culturales, que incluyen las formas de uso del suelo, las redes de infraestructuras, lo urbano-arquitectónico, lo arqueológico, lo intangible, etc.; iii) visuales-perceptuales, que comprenden visibilidades determinadas por las divisorias de aguas y formas geomorfológicas identificables por texturas, colores, etcétera. En definitiva, el método involucró efectuar diferentes pasos a la vez. El primero se hizo considerando el criterio de homogeneidad, al decidirse incluir toda el área de estudio -área declarada y de amortiguación-, entendida como la suma de las cuencas hidrográficas de los ríos Grande y El Aguilar, las cuales se subdividen a su vez en cuencas menores, sobre las cuales se localizan los asentamientos siguiendo el principio del determinismo geográfico. El estudio de los límites físicos de las cuencas se hizo a través de Google Earth mediante la navegación a vuelo de pájaro y los cortes de perfiles, lo que permitió determinar las divisorias de aguas como líneas demarcatorias de los campos visuales. Luego se procedió a combinar el componente natural con el cultural. Se empleó para ello Street View junto con Google Earth, identificándose la red de circulación -vías férreas, rutas pavimentadas, caminos de tierra y senderos peatonales- y los sitios de asentamientos humanos dispersos. En el área de amortiguación especialmente, los aspectos culturales expresaron una particular relación con los trazados viales peatonales en la localización de todo tipo de asentamientos, incluso aquellos sistemas de viviendas dispersas y corrales distribuidos a lo largo y ancho del territorio quebradeño. La posterior adición de los otros recursos contribuyó finalmente a la obtención de información suficiente para formular una primera propuesta de unidades paisajísticas. Esta pretende responder a criterios científicos e incluir la mayor cantidad posible de recursos inventariados, otorgando posibilidades a los lugares menos reconocidos. Cuando el inventario contenga la cantidad de recursos 
que se ha fijado como meta y se concluya el catálogo, será el momento de evaluar la validez de la determinación de dichas unidades (Figura 8, Figura 9 y Figura 10).

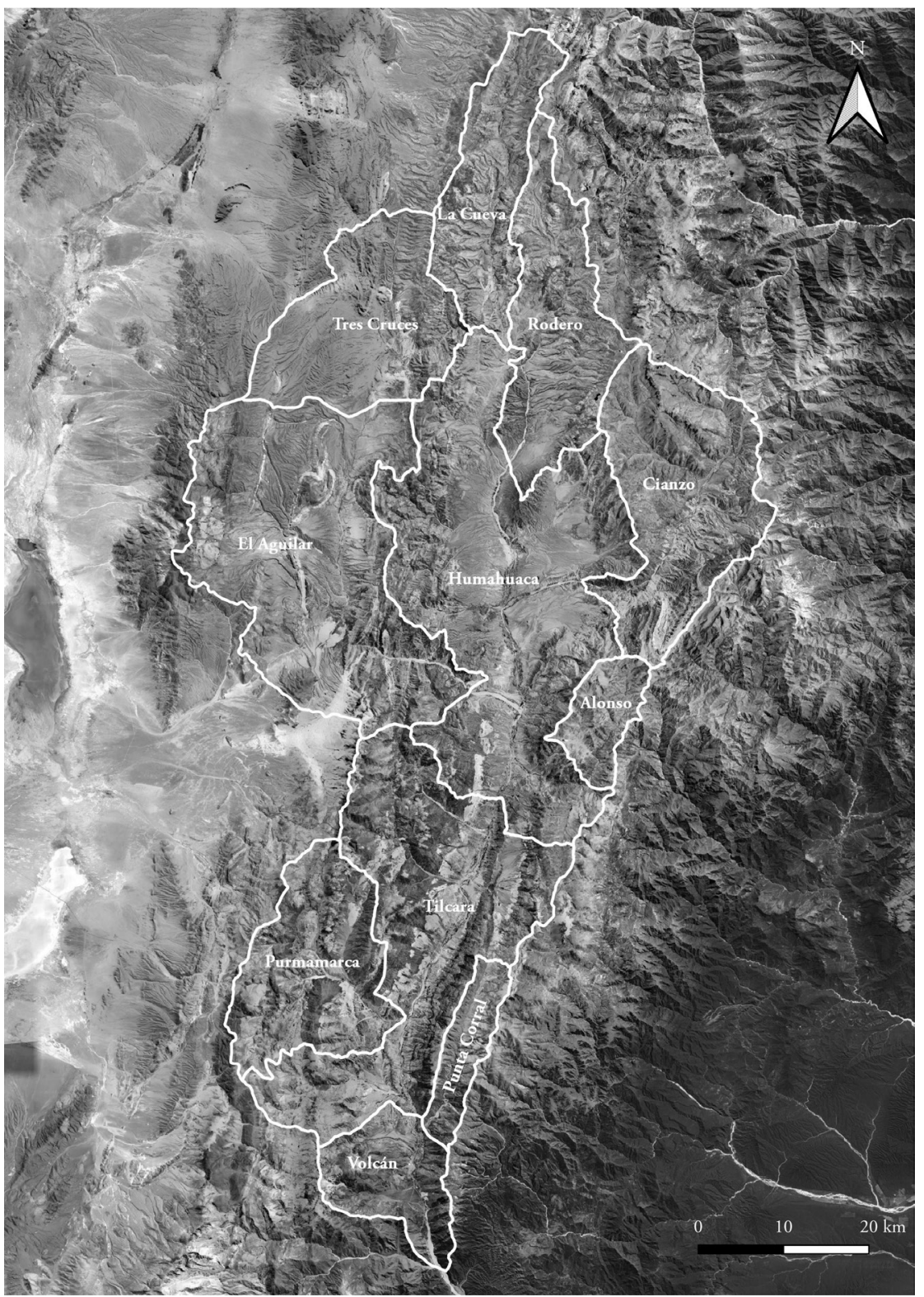

FIGURA 8 | Determinación de unidades de paisaje cuyas denominaciones hacen referencia al asentamiento humano de mayor jerarquía localizado dentro de la unidad

NOTA OBSÉRVESE QUE LAS LÍNEAS DIVISORIAS COINCIDEN CON LAS CUMBRES DIVISORIAS DE AGUAS FUENTE ELABORACIÓN PROPIA SOBRE LA BASE DE GOOGLE SATELLITE 


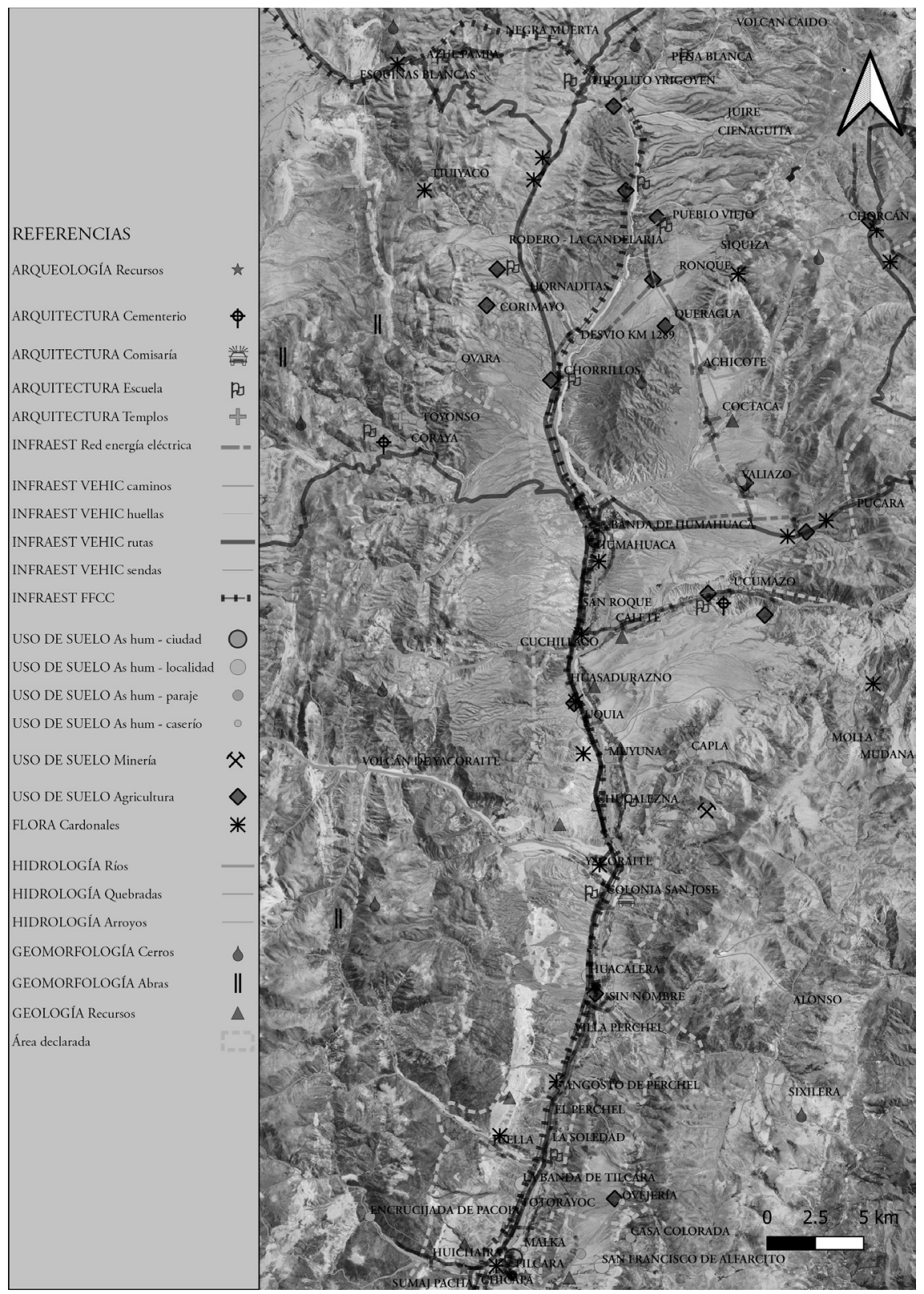

FIgURA 9 | Detalle de la unidad de paisaje de Humahuaca con localización de recursos paisajísticos

FUENTE ELABORACIÓN PROPIA SOBRE LA BASE DE GOOGLE SATELLITE 


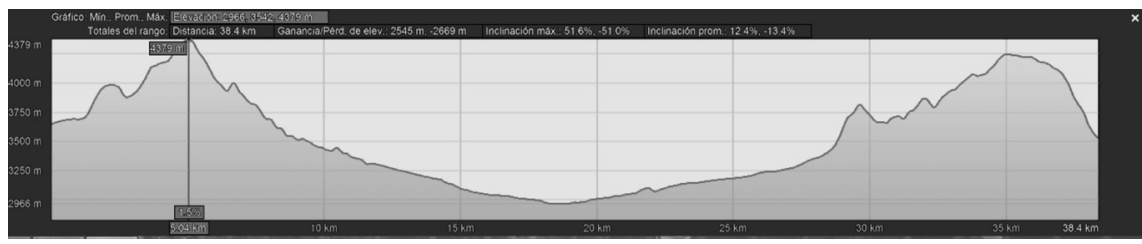

Figura io | Perfil de la unidad de paisaje de Humahuaca tomado de este a oeste FUENTE ELABORACIÓN PROPIA

\section{Notas de cierre: hacia una valoración del método}

Hasta aquí se ha pretendido dar a conocer la metodología para el desarrollo del inventario de recursos paisajísticos desde una idea de organización sistémica y holística, partiendo de la necesidad de unificar los datos en un documento único. Se establecen algunas notas de cierre que consideran el análisis de antecedentes, las ventajas del enfoque integral, la flexibilidad del método, el incremento en la visibilidad de componentes y, finalmente, las posibilidades operativas en términos de gestión futura, así como el aporte de esta metodología.

A partir de los antecedentes analizados, pueden considerarse dos cuestiones acerca de la conceptualización de la denominación 'inventario' y de la metodología. Por un lado, y como ya lo habíamos afirmado, los términos 'inventario' y 'catálogo' se usan indistintamente para establecer la identificación y documentación de un paisaje. Por otro, procedimentalmente se pudo precisar dos formas de encarar un estudio: partir de lo general hasta llegar al detalle de componentes o tipos de paisajes, o realizar una lista de elementos caracterizadores para luego definir los aspectos generales que los identifican. Cualesquiera que sean el camino, la escala o el método, los estudios tuvieron como fin último la gestión del paisaje y/o su planificación o monitoreo. Durante el proceso, las instituciones que llevaron adelante este tipo de trabajos generaron guías procedimentales de carácter amplio, guías con casos ejemplificadores o simplemente un inventario exhaustivo.

En cuanto a la flexibilidad del método, la incorporación del concepto work in progress permitió generar una malla abierta con una perspectiva estratégica de incorporar recursos paisajísticos para ser identificados de forma continua, saliendo del concepto de inventario cerrado y pensando en un producto que puede construirse y validarse con el aporte de diversos actores sociales.

Consideramos que el trabajo da cuenta de una mirada que se abre desde un enfoque a la individualidad del recurso para avanzar a otro global y multidisciplinar, dando un complejo salto por sobre las barreras o fronteras disciplinares. Este hecho dio cabida a una visión que abarca diversas escalas, superando la arquitectónica y urbana e integrando recursos de otras disciplinas -como la geología y la geomorfología o el aspecto inmaterial-, dimensiones que antes el equipo no tenía capacidad de incorporar al observar un bien.

En referencia a la posibilidad de interrelacionar componentes complejos, el pensamiento sistémico permitió analizar al territorio desde una mirada integral. En virtud de ello, la matriz de datos, junto con la cartografía sIG, facilitaron la 
identificación de la diversidad de componentes y la determinación de relaciones entre ellos a través de distintas jerarquías de escalas.

La visibilidad de un número mayor de componentes se hizo presente en la cantidad de bienes paisajísticos identificados, hecho que permitió establecer una ponderación de valores y detectar los componentes degradados para planificar un proceso de gestión. De este modo brindó, además, la posibilidad de hacer visibles algunos recursos que no estaban legitimados. Por ejemplo, los lugares de la "señalada" del carnaval (sitios en los que por tradición se realiza un determinado corte en la oreja del animal para su reconocimiento) pueden ser incluidos, porque se entiende el valor de la costumbre más allá del espacio físico donde se desarrolla el acto central de la fiesta.

Sintetizando, la propuesta consistió en inventariar los componentes paisajísticos a la manera de elementos de un mosaico, es decir, registrando cada subsistema de recurso paisajístico para luego recomponer el sistema, entendiendo durante el proceso la visión holística que considera el total más que la suma de las partes. Esta mirada integral condujo a un punto de inflexión, pues dejó atrás la mirada del patrimonio como monumento, desde las disciplinas de la arquitectura y el urbanismo, para aproximarse hacia una visión integradora y sistémica, desde el ámbito multidisciplinar. El cambio ya estaba anunciado cuando Cruz Pérez y Español Echañiz (2009) afirmaron hace algunos años que "la evolución del concepto de patrimonio cultural fue cambiando desde patrimonio monumental, asociado a la calidad artística, hasta el paisaje considerado como valor colectivo" (p. 37).

En otro orden, la propuesta metodológica abre una puerta hacia la optimización de un proceso de gestión que se inició con el conocimiento de los recursos. El inventario constituyó la herramienta clave debido a la inexistencia de estudios de paisaje en el área o de inventarios patrimoniales con un enfoque holístico. Permitió, además, el conocimiento del bien inventariado de acuerdo a una serie de categorías de información que, en la etapa siguiente, contribuirán a la construcción de un catálogo de paisaje. En dicho documento intervendrán pautas de selección y distintas variables de análisis que permitirán llegar a resultados de diagnóstico y valorativos; y estos, a su vez, a la elaboración de instrumentos de protección y planes de concienciación. De este modo, podemos aventurar que las posibilidades operativas en términos de gestión futura involucrarían: i) la valoración a partir de la consideración de las variables cualitativas de los bienes, donde además sea posible ponderar el papel que desempeñan en la conformación del paisaje para un posterior establecimiento de políticas; ii) la validación de inventario y catálogo, mediante el consenso de la comunidad y de actores implicados; iii) la difusión, mediante el desarrollo de medios digitales y técnicas participación social; iv) la intervención, a nivel participativo, en temas de la generación de políticas de paisaje; v) la protección jurídica que, en su primera fase, atenderá las áreas de mayor concentración de recursos paisajísticos, y en la última, los paisajes degradados, con el fin de orientar el accionar de las diferentes regiones en diversas áreas o aspectos en materia de protección, gestión y mejora; y vi) el monitoreo, como medio de observación continua que permita corregir, ratificar o proponer nuevas estrategias. Todas estas actividades 
no necesariamente seguirán una secuencia lineal, pudiendo realizarse en paralelo, anticiparse o repetirse, según las necesidades del proceso.

Para finalizar, podría considerarse que el inventario desarrollado para la Quebrada de Humahuaca aporta lo siguiente: i) Es una herramienta que facilita el inicio de los estudios de paisaje, para los casos de inexistencia de documentación o para las áreas menos consolidadas o no consolidadas desde el punto de vista de la planificación; ii) Facilita una cuantificación de los componentes abierta a incrementarse en lo sucesivo -de ahí su propiedad de flexibilidad-, al tiempo que posibilita establecer las relaciones entre componentes por superposición y su lectura a partir de la interdisciplinariedad -de ahí su condición de holístico y sistémico-; iii) Permite visibilizar, identificar y geolocalizar rápidamente un componente de paisaje, abriendo paso con ello a una actuación rápida o protección en caso de necesidad; iv) Posibilita una lectura analítica con dos entradas diferentes: una donde el paisaje tiene la particularidad de poder verse en sus cuestiones descriptivas o caracterizadoras integrales, y otra en que puede mirarse el componente en forma totalmente individualizada en su interacción con el resto; v) Permite detectar áreas de concentración de recursos y una gran diversidad de tipos de componentes; vi) La matriz de datos en simbiosis con la cartografía posibilita una visión panóptica del sistema; vii) Permite desarrollar un orden en la visión sistémica de lo analítico y lo sintético; viii) Da cuenta de la experiencia de haber desarrollado una metodología adaptada al sitio, pero a la vez aplicable a otros sitios, con la particularidad de que puede modificarse. En otro orden, ix) Abre una puerta posible para aquellos lugares en los cuales los antecedentes de inventarios patrimoniales, o estudios referentes al sitio o al paisaje, se encuentran dispersos, sin la suficiente transferencia al medio; y x) Constituye un modo de integrar valiosos trabajos de investigación desarrollados por otros investigadores, que no han sido difundidos o reunidos por las instituciones o actores encargados de la gestión.

La meta del inventario se orienta, como muchos otros, a conocer los paisajes, detectando señas de identidad para educar, sensibilizar y actuar, teniendo como fin último la protección de un paisaje cultural declarado patrimonio mundial que conserve los valores naturales y culturales que el sitio posee, y lograr un equilibrio entre conservación y desarrollo.

\section{Referencias bibliográficas}

Aubel, C., Bigot, C., Collin, M. \& Minier, J. P. (1999). Inventaire des paysages de Poitou-Charente. Poitou-Charentes: Conservatoire d'espaces naturels, Ministère de l'Aménagement du Territoire et de l'Environnement et de l'Union Européenne. http://www.paysagepoitou-charentes.org $/ \mathrm{Pb} 532 . \mathrm{html} ? \mathrm{~d}=16 \& \mathrm{c}=1 \& s=1 \& \mathrm{n}=\mathrm{p} \& \mathrm{~g}=\& \mathrm{e}=. \mathrm{html}$

Ballén Ariza, M. (2007). Abordaje hermenéutico de la investigación cualitativa. Teorías, procesos, técnicas. Bogotá: Universidad Cooperativa de Colombia. 
Bôas Camargo, G., Storchi, M. \& Nór, S. (2015). Inventário de paisagem cultural de Florianópolis. Universidade Federal de Santa Catarina. https://issuu.com/mauriciostorchi/docs/ ipc_2015_-_folha__nica

Bold, J. (2009). Guidance on inventory and documentation of the cultural heritage. Strasbourg Cedex: Council of Europe.

British Columbia Ministry of Forests. (1997). Visual landscape inventory. Procedures \& standards manual. Preparado por British Columbia Ministry of Forests, Forest Practices Branch for the Culture Task Force, Resources Inventory Committee. Victoria, Columbia Británica: Resources Inventory Committee, Ministry of Forests. https://www2.gov. bc.ca/assets/gov/environment/natural-resource-stewardship/nr-laws-policy/risc/vli. pdf

Brown, N., Hasty, D., Keohan, T. \& Terzis, L. (2001). More than a database: The National Park Service's Cultural Landscapes Inventory improves resource. Crossing boundaries in park management: Proceedings of the 11th Conference on Research and Resource Management in Parks and on Public Lands. Hancock, MI: The George Wright Society. http://www. georgewright.org/53brown.pdf.

Chalana, M. (2010). Preservation, education \& research. Vol. III. Seattle, WA: University of Washington. http://ncpe.us/wp-content/uploads/2012/07/Chalana.pdf

Consejo de Europa (2000). Convenio Europeo del Paisaje. Florencia. http://www.upv.es/ contenidos/CAMUNISO/info/U0670786.pdf

Conselleria de Territorio y Vivienda (2006). Caracterización de los recursos paisajisticos en Reglamento de Paisaje de la Comunitat Valenciana. Decreto 120/2006. Art 32. http:// noticias.juridicas.com/base_datos/CCAA/va-d120-2006.t3.html

Cruz Pérez, L. \& Español Echarriz, I. (2009). El paisaje. De la percepción a la gestión. Madrid: Liteam.

Dalbem, R., de Moura, A., Jorge, F., Morokawa, M. \& Valaski, S. (2005). Delimitaçáo de unidades de paisagem: conceito e método aplicados ao Município de Paranaguál PR/ Brasil. Anais do XI Simpósio Brasileiro de Geografia Física Aplicada. São Paulo: Universidade de São Paulo. https://docplayer.com.br/40332134-Delimitacao-deunidades-de-paisagem-conceito-e-metodo-aplicados-ao-municipio-de-paranagua-prbrasil.html

Departamento de Medio Ambiente, Planificación Territorial y Vivienda. Gobierno Vasco (2016). Guía para la elaboración de estudios de integración paisajistica en la comunidad autónoma del País Vasco. Vitoria-Gasteiz: Tecnalia Inspiring Business. http://www. euskadi.eus/contenidos/informacion/presentacion_paisaia/es_def/adjuntos/Guia\%20 paisaje_FINAL.pdf

Federación Internacional de Arquitectos Paisajistas (FIAP). (2013). La iniciativa latinoamericana del paisaje. https://laliniciativablog.files.wordpress.com/2013/04/lali_esp_reducida. pdf

Ferrari, M. \& Paterlini, O. (2013). La conservación de la autenticidad y la integridad del paisaje cultural como bases de los procesos de gestión. Revista PH. Sección Bienes, paisajes e itinerarios [Instituto Andaluz del Patrimonio Histórico], (84), 86-107. https://doi. org/10.33349/2013.84.3407 
Heritage Resources Centre. (2004). Cultural heritage landscape inventory background resources. Waterloo, Ontario: Regional Municipality of Waterloo. https://uwaterloo.ca/ heritage-resources-centre/sites/ca.heritage-resources-centre/files/uploads/files/12\%20 Region\%20CHL\%20-\%20with\%20title\%20page_0.pdf

José, N., Albeck, M. A., Rodríguez, L., Solís, N., Lupo, L., Losada, F., Chalabe, F. \& Hopkins, F. (2002). Quebrada de Humahuaca. Un itinerario cultural de 10.000 años. Propuesta para la inscripción a la Lista de Patrimonio Mundial de la Unesco. Jujuy: Gobierno de la Provincia de Jujuy.

Junta de Castilla y León. Consejería de Medio Ambiente. (2007). Inventario Recursos de Baja Intensidad. Lugar de Interés Comunitario Sabinares Sierra de Cabrejas. Soria: Asociación de Tierras sorianas del Cid. https://docplayer.es/43208139-L-i-c-sabinares-sierra-decabrejas-inventario-recursos-de-baja-intensidad.html

Larive López, E. \& Segura Raya, M. V. (2013, nov. 16). Entrevista personal sobre Sistemas de Información Geográfica (sIG) y aplicaciones al paisaje cultural en Sevilla.

Litton, R. B. Jr. (1968). Forest landscape description and inventories - A basis for land planning and design. Berkeley, CA: Pacific Southwest Forest and Ranch Experiment Station. Forest Service, us Department of Agriculture. https://www.fs.fed.us/psw/publications/ documents/psw_rp049/psw_rp049.pdf

Litton, R. B. Jr. \& Tetlow, R. J. (1978). A landscape inventory framework: Scenic analyses of the Northern Great Plains. Berkeley, CA: Pacific Southwest Forest and Range Experiment Station. https://www.fs.fed.us/psw/publications/documents/psw_rp135/psw_rp135. pdf

Ministère de l'Equipement, du Logement et des Transports. Direction de l'Architecture et de l'Urbanisme (1995). Inventaire et typologie des paysages du Finistere. Quimper: Ouest Aménegement Bureau d'Etudes. http://www.finistere.gouv.fr/Politiques-publiques/ Amenagement-du-territoire-construction-logement/Connaissance-du-territoire/ Paysages/Inventaire-des-paysages-du-Finistere-de-1995\#

Montaner, J. M. (2008). Sistemas arquitectónicos contemporáneos. Barcelona: Gustavo Gili.

Moreira Madueño, J. M. \& Naranjo, Z. (Coords.). (2014). Bases para la realización del Sistema Compartido de Información sobre el Paisaje de Andalucía (SCIPA). Sevilla: Junta de Andalucía. Consejería de Medio Ambiente y Ordenación del Territorio. http:// paisajeyterritorio.es/assets/sciap-sierra-morena.pdf

Naveh, Z., Lieberman, A., Sarmiento, F., Ghersa, C. \& León, R. (2001). Ecología de paisajes. Teoría y aplicaciones. Buenos Aires: Editorial Facultad de Agronomía, Universidad de Buenos Aires.

Page, R. (2009). Cultural landscapes inventory. Professional procedures guide. Washington DC: u.s. Department of the Interior. National Park Service. Cultural Resource Stewardship and Partnerships. Park Historic Structures and Cultural Landscapes Program. https:// babel.hathitrust.org/cgi/pt?id=uva.x006093995; view=1 up;seq=7

Page, R., Gilbert, C. \& Dolan, S. (1998). A guide to cultural landscape reports: contents, process, and techniques. Washington, DC: U.s. Department of the Interior, National Park Service. Cultural Resource Stewardship and Partnerships. Park Historic Structures and Cultural Landscapes Program. https://www.nps.gov/parkhistory/online_books/nps/ cl_reports.pdf 
Palmerston North City Council. (2011). Palmerston North Landscape Inventory. Wellington: Opus International Consultants. https://www.pncc.govt.nz/media/2630582/dms_849846-v1-palmerston_north_landscape_inventory_2011.pdf

Pérez Alberti, A., Borobio Sanchiz, M., Castillo Rodríguez, F. \& Payán Pérez, M. (2014). Metodología y clasificación de tipos de paisaje en Galicia. GOT, Revista de Geografia e Ordenamento do Território, (6), 259-282. https://dx.doi.org/10.17127/got/2014.6.015

Períes, L., Ojeda, B. \& Kesman, C. (2012). Catálogo del paisaje del río Suquía en la ciudad de Córdoba. Córdoba: Editorial de la Universidad Católica de Córdoba.

Romero, G. \& Mesías, R. (Coords.). (2004). La participación en el diseño urbano y arquitectónico en la producción social del hábitat. México: Programa Iberoamericano de Ciencia y Tecnología para el Desarrollo. México DF: CYTED-HABYTED-Red XIV.F. http://cdam. unsis.edu.mx/files/Desarrollo\%20Urbano\%20y\%20Ordenamiento\%20Territorial/ Otras\%20disposiciones/Participaci\%C3\%B3n_dise\%C3\%B1o_urbano.pdf

Sauer, C. O. (1925). The morphology of landscape. Berkeley, ca: University of California Press.

Sochava, V. B. (1978). Vvedenie v uchenie o geosistemakh [Introducción a la doctrina de los geosistemas]. Novosibirsk: Naouka.

Swanwick, C. (Dir.) (2002). Landscape character assessment. Guidance for England and Scotland. Gloucestershire, Edinburg: The Countryside Agency - Scottish Natural Heritage. https:/www.nature.scot/sites/default/files/2018-02/Publication\%202002\%20-\%20 Landscape $\% 20$ Character $\% 20$ Assessment $\% 20$ guidance $\% 20$ for $\% 20$ England $\% 20$ and $\% 20$ Scotland.pdf

Vázquez Estrada, A. \& Bedoya, M. L. (2015). Guia metodológica para el paisaje cultural ecuatoriano. Quito: Instituto Nacional de Patrimonio Cultural. http://www.amevirtual. gob.ec/wp-content/uploads/2017/04/GUIA-METODOL\%C3\%93GICA-PARAEL-PAISAJE-CULTURAL-ECUATORIANO.pdf

Warrack, M. (Dir.). (2005). Cultural landscape inventory City of Mississauga. Mississauga: The Landplan Collaborative Ltd., Goldsmith Borgal \& Company Ltd., North South Environmental Inc., Geodata Resources Inc. http://www5.mississauga.ca/pdfs/ Cultural_Landscape_Inventory_Jan05.pdf

Williamson, R. (Dir.). (2010). City of Vaughan Official Plan: Cultural heritage landscape inventory and policy study. Toronto: Archaeological Service Inc. https://www.vaughan. ca/projects/policy_planning_projects/Pages/Background-Papers-and-Studies.aspx 